\title{
Australia's National Disability Insurance Scheme: looking back to shape the future
}

\section{Dr Michael Kendrick}

Kendrick Consulting International, USA

4 Bullard Avenue, Holyoke, MA 01040 USA

Ph: +1 413/533-3511

Mob: +1 413/575 8522 (mobile)

Email: kendrickconsult@icloud.com

\section{Dr Margaret Ward (Corresponding Author)}

Griffith University, School of Human Services and Social Work, Australia

Research Fellow

School of Human Services \& Social Work, Griffith University

Room L03_3.22 Griffith University, MEADOWBROOK QLD 4131

Ph: +61 733821453

Mob +61 409898498

Email: margaret.ward@griffith.edu.au

\section{Professor Lesley Chenoweth AO}

Griffith University, School of Human Services and Social Work, Australia

ProVice Chancellor \& Head Logan Campus

Room 103_3.19 Griffith University, MEADOWBROOK QLD 4131 |

Ph: +61 733821005

Mob +61 409853369

Email l.chenoweth@griffith.edu.au 


\title{
Australia's National Disability Insurance Scheme: looking back to shape the future
}

\begin{abstract}
Australia's National Disability Insurance Scheme (NDIS) provides a once-in-ageneration opportunity to transform how people with a disability are served. Similar to the enactment of the Disability Services Act 1986, which challenged the segregation and supported the integration of people with a disability into community settings, the National Disability Insurance Scheme Act 2013 is expected to fundamentally disrupt traditional service practice and improve disabled people’s lives.

This paper identifies some lessons from the previous reform of 1986 to guide policy makers, people with a disability, their families and service-providers, as they implement the NDIS now. It reflects on what it takes to make change and what can be expected to remain essentially the same regardless of the disruption that the NDIS will bring. It concludes that if the lessons of the past hold true, the NDIS will require several decades of intentional leadership and capacity-building to achieve enduring, positive change.
\end{abstract}

\section{Key words}

National Disability Insurance Scheme, support, funding, future, history

\section{Introduction}

In Australia, the newly-established National Disability Insurance Scheme (NDIS) offers people with significant disability a measure of entitlement to support, greater choice and control in the delivery of that support, more personalised service delivery and portability of funding across the country. The NDIS, which was established by the National Disability Insurance Scheme Act (NDIS Act) (Commonwealth of Australia 2013), is the first major legislative reform in disability service provision in Australia since the Disability Services Act 
(DSA) (Commonwealth of Australia 1986) almost thirty years ago. This paper seeks to identify lessons from the past that might assist the NDIS to bring positive and enduring reform for people with a disability.

The rhetoric that accompanied the DSA in the 1980s is surprisingly similar to that which now accompanies the NDIS Act. Both motivated people with a disability, families and professionals towards the ideals of human rights, social inclusion and participation. The DSA made many gains; nevertheless, it ultimately failed to deliver (National People with Disabilities and Carer Council, 2009), leaving people with a disability with a service system that was described as 'irretrievably broken and broke, chronically under-funded and underresourced, crisis driven, [and] struggling against a vast tide of unmet need' (18). This time around, the architects of the NDIS rejected the traditional model of funding service agencies for a 'social insurance' model which adopts a 'shared risk of disability' across the Australian population. The NDIS entitles people with a disability to a level of support and shift the authority over service design and direction from service-provider to service-user (Productivity Commission 2011, 11).

The paper first gives some background to the DSA and the NDIS Act, and reports on the progress of the NDIS thus far. It then identifies six broad lessons from the last thirty years since the DSA. Regardless of these fundamental systemic changes and initial positive outcomes, conventional agencies will continue to find change difficult. They will also continue to find some people difficult to serve. Entitlement to the NDIS will not be absolute and governments will inevitably disappoint as their policy rhetoric shifts and changes with new political, economic and bureaucratic priorities. People with a disability will still require much more than 'choice and control' over funding and services to have a good life. They will need the active involvement of family, friends and natural networks. Finally, positive values 
and vision accompanied by independent advocacy will still be crucial if enduring progress is to be made.

As in the past, a component of people with a disability, families and their allies are likely to continue to lead much of the reform and also to provide much of the innovation. The NDIS would be wise to maintain close alliances with change agents 'on the ground'. It will take significant political will to keep people with a disability central, as the NDIS may be required to serve other more powerful agendas and interests. The paper concludes that decades of intentional capacity-building, nurturing of principled leadership and vigorous independent advocacy will be required before the vision of the NDIS transforms into enduring and positive change for people with a disability.

\section{Background}

Since the middle of the last century, the lives of people with a disability have improved and changed alongside the development of a disability service system (Kendrick 2012). Initially, families of children with a disability had two options: placement in an institution or to be left to provide the care themselves. This situation remained largely unchanged until the Australian Government commenced programs to support community living for both people with a disability and older people in the mid-1980s (Chenoweth 2000).

Social policy on people with a disability, including the enactment of the DSA, had three major influences at the time: the human rights movement, which now specifically included people with a disability (United Nations 1971, 1975); the principle of normalisation (Nirje 1969) and the subsequent theory of social role valorisation (Wolfensberger 1983); and social model of disability (Finkelstein 1981). Some would argue that along with these theoretical drivers was a more pragmatic economic one, which was to manage the burgeoning cost of specialist facilities that were ageing (Wiesel and Bigby 2015). 
Chenoweth (2000) observes that resistance to this change came from two quarters: people with vested interests in specialist facilities; and families who had institutionalised their family member previously due to the lack of alternatives. This resistance impeded reform somewhat and justified conventional agencies to continue to congregate and segregate people with a disability. These practices could also be blamed on the continuation of traditional funding models, chronic funding shortages and the management of subsequent ongoing crises (National People with Disabilities and Carer Council 2009, 11).

Not all services maintained these traditional practices; a number of small initiatives emerged as a direct outcome of the DSA to interpret the legislation's original intent and to demonstrate more flexible and individualised responses, self-direction and community living. These were historically most prominent in Western Australia (Bartnik and Chalmers 2007, Lord and Hutchison 2003), and otherwise strikingly small in number in the other states and territories (Kendrick 2009). There are, however, enough instances of people with significant disability who benefitted from the policy changes of the 1980s and have lived full, ordinary lives for many years in the community. They indicate that achieving the NDIS objectives is possible for greater numbers providing that the lessons learned are incorporated in future capacity building strategies.

Early in the establishment of the NDIS, many people with a disability made decisions to change their circumstances. They appear to be people who have capacity, supportive networks and a positive vision for themselves, and are using the opportunities presented by the NDIS to leave the conventional service system for more flexible options (Mavromaras, Moskos, and Mahuteau 2016). This has been the experience where self-direction is practiced elsewhere (Glendinning 2008, Timberlake et al. 2014, Swaine et al. 2016, Lakhani, McDonald, and Zeehan 2016). At first glance, the NDIS Act has succeeded where the DSA failed. The Agency’s (2016) recent annual report notes a 95\% participant satisfaction rate; the 
Australian community agreed to an increased tax to pay for the NDIS (Swann, Gillard, and Macklin 2013); and many people with a disability and professionals are proving to be highly motivated by the idea of choice and control for people with a disability (RichmondPRA 2013, National Disability Practitioners 2014, NDIS 2015).

The NDIS has a number of ambitious aims. One is entitlement for people with a longterm disability to 'reasonable and necessary' supports. Another is that the NDIS requires people with a disability and families to plan and potentially implement what is planned. If this is well done, the process will empower people to direct their own lives and to avoid crises. The NDIS aims to improve the wellbeing of people with a disability by being able to choose, change and oversee their supports, and to make the service industry more responsive through the mechanisms of a market-driven economy based on the demands of people with a disability. The NDIS also aims for people to achieve social and economic participation through increased independence and to give greater acknowledgement and respect to the role of families and informal networks. Finally it aims to reduce long-term costs through early intervention and timely action. Early indicators are that participants and their families report an overall increased perception of wellbeing, and the NDIS has significantly disrupted many established support practices, including changes in business models, mergers and departures from the sector, and changes how services relate with each other (Mavromaras, Moskos, and Mahuteau 2016).

The experience of the last thirty years shows that social reform for people with a disability is complex, and this initial blush of success might hide the long-term developmental challenges that lie ahead for the NDIS, given its ambitious aims. For example, how 'choice and control' is interpreted in practice by service-users and service-providers is likely to diverge considerably, and the shift in authority is already having little or negative impact on people who have been disempowered by years of marginalisation, struggle and 
disappointment (Mavromaras, Moskos, and Mahuteau 2016), and for the traditional agencies that continue to support them (National Disability Services 2015).

A core underlying issue for the NDIS is the legacy of the DSA; that is, misalignment among their valid and ambitious ideals, the individual aspirations of people with a disability, and the widespread inability and often unwillingness of the service system to respond meaningfully. This paper does not attempt to provide an answer to this problem; rather, it identifies six lessons from the implementation of the DSA, and some actions for changeagents to assist enduring positive change for people with a disability through the NDIS.

\section{Six lessons from the past}

\section{Conventional services will continue to find change difficult}

Noted earlier, instances of responsive individualised service espoused by the NDIS have been practiced for some time in small numbers to varying degrees across Australia (Ottmann, Laragy, and Haddon 2009). Notwithstanding the exceptional government leadership in Western Australia (Bartnik and Chalmers 2007, Lord and Hutchison 2003), the change agents who pioneered them have largely been people with a disability, their families and professionals who were inspired by the rhetoric of the DSA, rejected the limiting practices of conventional agencies, and innovated with self-direction within the limitations of the available funding programs.

The conventional agencies have, until now, expressed little interest in assisting people with a disability to direct their own support, and have been unwilling to learn from the early innovators of self-direction (Kendrick 2009). This perhaps stems from their significant investment in property, fixed service models and increasingly corporate organisational structures that distance the decision-makers from the people they serve: 
Since very few [of these] services in the present era are actually steered by service-users acting on free agency, [self-directed] arrangements are outside the usual experience of most administrators and professionals, making it extremely difficult for them to imagine anything other than what they have seen thus far. (Kendrick 2009, 92)

The considerable dominance these conventional agencies have had over people with a disability and their families was and continues to be tolerated because of their perceived reliability in assuring ongoing secure services is preferred over both the uncertainty and perceived risk inherent in innovative alternatives (Mavromaras, Moskos, and Mahuteau 2016). It can be expected that they will continue to make a convincing case that their clientele should remain in familiar arrangements, and many people will likely to do so for the time being.

The more realistic hope given the past experience with self-directed options is for incremental change, person by person electing for more individualised and self-directed options as their peers demonstrate they can determine the direction of their own lives. The speed of this transformation will vary from State to State. Western Australia has encouraged people with a disability and their families to self-direct for decades (Bartnik and Chalmers 2007) and this practice is now well-established (Disability Services Commission 2015). In contrast, New South Wales, Queensland and South Australia have only recently gained a small measure of such experience, and it undoubtedly will be harder for many services to make this fundamental change in a short time. In fact, it is difficult to identify more than a handful of conventional agencies in Australia that have sizably converted their services from congregate care (such as group homes, sheltered workshops and day centres) to exclusively individualised options. This is despite the three decades of person-centred rhetoric from the $D S A$, successful demonstrations of self-direction both in Australia and abroad, and the implementation of the NDIS to date. 
The NDIS invested significant resources in service transformation and capacity building prior its implementation. It would be wise for the NDIS to evaluate the real outcomes for people with a disability, in time, so that both capacity building and service transformation strategies are selected in the future on their proven merit. Should agencies fail to generate the anticipated improved outcomes, individuals who use these agencies might well benefit from intensive independent support to consider and ultimately to take up more responsive alternatives, and make them much less reliant on services that cannot generate positive outcomes. This was learned in the Western Australian system over several decades (Bartnik and Chalmers 2007).

\section{Services will continue to find people difficult to serve}

Australia's past service system identified some people as 'difficult to serve'; the service model as practiced and the person being served did not match, though the service-provider might commonly portray the problem as being essentially with the person, not the service. When people are put in the wrong setting or with the wrong support arrangement at the wrong time, there will inevitably be difficulties. More responsive agencies have learnt in the last thirty years that, to meet people's support needs well, they must have the capacity to start with each person, have the flexibility to get the support right and be able to tailor that support over time. The better the support fits the person and the easier it is able to adapt and change to the person's expressed, emerging or changing needs, the better the outcomes (Coulson 2007).

Many services inspired by the DSA began with a high level of flexibility and, over time, the rules tended to accumulate to form standardised and increasingly rigid and largely non-negotiable solutions. A form of atrophy set in and created smaller pockets of institutional and custodial culture and practices, which tended to serve the needs of the staff and the service organisation before those of the people being served (Robinson and Chenoweth 2011, 
Bigby et al 2012). The disability sector has also witnessed a gradual shift from family and community initiated and governed services to organisations with highly corporate-style governance, 'content-free' management and adherence to technocratic solutions resulting in staff less willing to use their personal discretion, take reasonable risks or find creative solutions to problems (Wills and Chenoweth 2005). Curiously, the emergence of the NDIS has, at least thus far, triggered a notable amount of service agency establishment, merger and exit activity; bringing in inexperienced players, creating even larger and more complex agencies working across state lines, and losing others that were not going to survive in a market-driven environment (Mavromaras, Moskos, and Mahuteau 2016).

The NDIS currently espouses a high level of flexibility and negotiability of service practices and theoretically offers people with a disability the opportunity to design and direct the service that fits best. It also offers the conventional service system a unique, historical opportunity to be able to start with the person and then subsequently to remain faithful to that person and their needs and priorities. The NDIS might learn from the pattern of a gradual weakening of resolve by service-providers to remain 'person-centred' evident prior to the NDIS, and to consider what can be done to prevent the same custodial atrophy even in comparatively newly-created individualised arrangements.

By default, the task has been handed to people with a disability, their families and friends in the name of 'market-forces' to safeguard this flexibility and negotiability by becoming discerning, skilled and assertive customers, and being wary of ready-made, prepackaged service solutions. They will also need to be both proficient customers (Mavromaras, Moskos, and Mahuteau 2016) and persistent advocates to keep the NDIS true to its person-centred intentions and obligations (Social Care Institute for Excellence 2015). While some individuals will (and have already) develop these capacities for themselves, it is unrealistic and unethical to rely on the most vulnerable people in the system to keep the 
system honest (Wolfensberger 2003, Glendinning 2008). Early indicators show that some people with an intellectual or psycho-social disability and some vulnerable families consider themselves worse off under the NDIS (Mavromaras, Moskos, and Mahuteau 2016).

This serves to question how people without capacity or supportive networks will protect their personhood and aspirations from a market-driven service sector with competing agendas that might not have their best interests at heart. The United Kingdom's experience of self-direction identifies a creative tension between individual arrangements and systemic safeguards; what might be over-protection for one person is under-protection for another (Manthorpe et al. 2011). With these factors of variable personal capacities and potentially inadequate supports in mind, the NDIS must ensure that, in its role of overseeing serviceprovider conduct, capacity-building and 'value-for-money' (NDIS 2015b), it adopts a systemic and enduring bias to compensate for the comparatively weak power of people with a disability and their families in relation to the service system rather than to assume that this issue has been resolved.

The NDIS would be wise not to overlook the time-tested safeguards of the last thirty years; independent advocacy, independent service-quality reviews, the presence of committed family and natural supporters, access to experienced mentors and leaders, and long-term, strategic capacity-building towards service transformation and innovation. These five strategies working together could potentially increase the chances for people with a disability and their families either to find their way to the right lifestyle and support arrangements relatively promptly or to create them themselves if need be (Individualised Funding Coalition for Ontario 2004, Frisch 2015). It is notable in this regard that the need for independent advocacy is expected to rise with the implementation of the NDIS, yet future funding arrangements remain undecided (DANA 2016, Department of Social Services 2016). 


\section{Entitlement will not be absolute}

The NDIS was launched on a theme of human rights, equity, service security and entitlement (Commonwealth of Australia 2013). Any entitlement needs to be specific; in this case, individual supports and funding are to be based on a uniform assessment process based on need (Productivity Commission 2011, 392). Participants would receive 'reasonable and necessary supports' to increase independence and social and economic participation (Commonwealth of Australia 2013, 4). Many people may consider this is an entitlement in absolute terms; after all, there has been limited critique of these government promises, and they have not yet been fully tested over a long-term time frame.

The lack of attention paid to the plight of people with a disability over the last thirty years offers a warning in this regard. Reforms for greater equity and inclusion for people with a disability have been consistently contested, watered down and underfunded in Australia for decades (National People with Disabilities and Carer Council 2009, Bostock and Gleeson 2004, Chenoweth 2000, Brown and Ringma 1989). The funding program that accompanied the DSA was never designed to meet the need (Baume and Kay 1995) and had to compete annually for a cut in the welfare budget. Grants to non-government agencies saw most of the funding flow to established service outlets rather than to the people with a disability where they were located (Lindsay 1996). In short, the funding strategy entrenched the very inequities that the DSA set out to overcome and most often left the service industry much more powerfully positioned and influential than the end-user.

It would be naïve in the extreme to expect future governments to give absolute or unchanging guarantees of financial resources, moral integrity, fairness or other desirable commitments to people with a disability. It would also be the case that service-user and service-provider vested interests will continue to be difficult to reconcile. The current positive attention on the NDIS is similarly likely to be diverted in time by other pressing 
issues and priorities, regardless of the commitment to security of support quite apart from some kind of entitlement. A case in point is Australia's forty-year old health-care system (Medicare) which was recently under attack by the incumbent government for budgetary and ideological reasons. The government at the time needed to find budgetary savings and had been convinced that people capriciously overused doctors' services (Grattan 2015).

All systems have limitations, and as Australia heads into an uncertain economic future, the NDIS will not be immune from intense scrutiny by government of what is 'reasonable and necessary' for people with a disability. The NDIS might even receive a backlash from an Australian public that is losing its sense of entitlement more broadly (Weatherley 1994, Tingle 2012). Certainly, government austerity and income inequality are growing in most western countries with worrying implications for the most vulnerable (Pikkety and Saez 2014).

The NDIS argues its case for entitlement on two fronts: the first is principled, the second is pragmatic. The principled argument stems from Australia's ratification of the United Nations' Convention on the Rights of Persons with Disabilities (UNCRPD) and its optional protocol (United Nations 2007); the pragmatic argument is that a national insurancebased approach will minimise the long-term impacts of disability and maximise social and economic participation (Productivity Commission 2011, 63). The NDIS intends to collect, analyse and exchange unprecedented data on the lives of people with a disability for actuarial analysis to manage the scheme. The architects of the Scheme understand the harsh realities of making such an ambitious reform sustainable in the long term:

Effective ongoing commercial management is essential to avoid a blowout in assessment outcomes (and the funding associated with them) and to ensure appropriate service utilisation and costs. Poor management is the largest risk to the scheme's sustainability, and thereby the largest risk to long-run reasonable support of people with a disability and their families. (Productivity Commission 2011, 39) 
Notwithstanding the tension between the principled and the pragmatic, it still remains necessary for there to be a commitment formally 'built in' to the NDIS to identify in good time where and when the intent of the NDIS falls short of its ideals in practice, and to have these shortcomings responsibly addressed as they emerge.

The explicit and credible means to do this are not immediately apparent, so this remains a crucial component of further 'systems-building' if the NDIS is to sustain its alliance with the actual needs of people with a disability and their families. To its credit, some of the publically released reviews of the NDIS, thus far, have been surprisingly and usefully critical of the NDIS, as well as influential in addressing the issues raised going forward (National Institute of Labour Studies 2015, HDG Consulting Group 2013). Nonetheless, there is essentially at present no significant investment in independent means by which people with a disability can influence, ensure and even control the necessary forthright critique of the NDIS that would keep the NDIS honest and faithful to its higher purposes. Simply consulting with people with a disability when that consultation is being shaped by other parties does not constitute 'independent oversight and monitoring'. Given the scale of the NDIS, it will be an unprecedented challenge to keep the voice of people with a disability at an equal level of power and influence sufficient to credibly counter the many powerful interests that can be expected to become entrenched in the system.

\section{Choice and control will not be enough}

When speaking of the NDIS, many people think of 'choice' and 'control' as an absolute - you either have these or you do not. This is, in part, because the rhetoric of choice and control was used by the Australian Government to sell the idea of self-direction and individualised funding to a broad audience (Every Australian Counts 2013, NDIA 2016). This strategy was successful because everyone wants some measure of normative choice and control in their lives. Yet, most people know that choice and control are on a continuum, and 
a continuum in different dimensions in life. In this sense, choice and control are always going to be issues to be negotiated to some degree.

Thirty years ago, the rhetoric of ‘community living' and 'social integration' was used similarly to challenge practices that excluded and segregated people, to motivate the disability sector to change, and to garner the support of the public (Handicapped Programs Review 1985, Office of Disability 1987). Over time, the implementation of the DSA led to a more finessed and realistic understanding of these terms, including the capacity of services, the power of valued social roles (Lemay 1999, Wolfensberger 1998), the importance of families and informal networks (Stainton and Besser 1998), the challenges and opportunities of real work and community life (Chenoweth and Stehlik 2004), and how services can work for optimal benefit to the people they serve (Kendrick 2011).

There will necessarily need to be an ongoing debate about what having 'choice and control' means in a similarly finessed and realistic manner, given that even an iota of either could potentially be adjudicated by the NDIS as being 'reasonable and necessary' (Commonwealth of Australia 2013, Section 34). It is exclusively up to the NDIS at the moment to decide such things. These potentially arbitrary and capricious judgments by unknown NDIS officials can and eventually will be tested through internal reviews, tribunal hearings and judicial processes. People with a disability have yet to know if their interests will be dealt with in a beneficial way.

The nominal presence of individualised funding and self-direction as programmatic features will not be panaceas for a broken service system; there are many challenges involved in using these effectively to make a person's life better. The application of the NDIS in everyday life across potentially many tens of thousands of lives across many years will be the long-term net test of its actual relevance and outcome. Hence, the question of what capacities and other supports might strengthen the hand of people with a disability and their families 
need also to be carefully examined. What else does the NDIS need to do to bring about actual meaningful performance outcomes both systemically and one person at a time?

It would be naïve to assume that, when people with a disability are given choice and control over the services they use, they will somehow know and can articulate clearly what they want out of life, and that services will inevitably align with them to do their bidding. Self-direction without discernment may even cause forced individualisation and isolation (Roulstone and Morgan 2009). The mere presence of self-direction does not automatically assert, decide or defend what brings about a better life, nor does it automatically make people creative. Being creative can mean struggle, discomfort, and doing something different with inevitable confusions, errors and setbacks. As has been evident in the last three decades, many people with a disability, families and professionals need help with all manner of challenges depending upon what they each uniquely feel is difficult or perplexing. Their capacities are quite regularly exceeded and taxed if the challenges are large enough, and they often cannot imagine a better life or effectively pursue it without some assistance quite apart from effectively overseeing each and all of the many tasks involved.

Noted earlier, the impetus for change in the past has largely come from smaller initiatives (rather than conventional agencies) that commit to work in ethical partnership or ‘right relationship’ (Kendrick 2011, 61) with people with a disability and their families (Dyke 2013, Burke 2012, Community Resource Unit 2013). These efforts were greatly assisted when government officials were willing to take risks and work with change agents 'on the ground' (Ward 2006).

This history suggests that the innovation and service transformation sought by the NDIS will not be led by the established service sector; rather, small pockets of change will pop up here and there where determined and resourceful local leaders relish the discomfort that comes with creativity and have deliberate and enduring agency transformation strategies 
in place. The diffusion of these innovations will be directly affected by the interest, political will and operational capacity of the NDIS (Davila, Epstein, Shelton, and Shelton, 2006). This has been the pattern of the last thirty years and there is no evidence emerging, thus far, that this pattern will change, at least in its fundamentals. Many may believe that such fundamentals have been somehow resolved, since the NDIS has been heralded as supposedly a 'breakthrough' rendering many of the problems of the past somehow as no longer of concern (NDIA 2016).

Significantly increasing funding and relying on the buying power of service-users to stimulate this creativity and innovation will likely not be enough, even though it will add new and ultimately useful potentials to the mix (Ferguson 2007). The NDIS would be wise to encourage innovation in two ways: first, to intentionally strengthen people’s capacities over a long period with this strategic possibility in mind; and second, to make alliances with these 'on the ground' leaders as agents of change. In theory, there is considerable scope for such productive collaboration. It is quite ambiguous as to whether the NDIS has such an explicit intention; its current practices neither prohibit such efforts, nor do they assure it.

This kind of partnering will require the NDIS to have competent and community-led capacity development as part of its day-to-day business, likely drawn from a strategy of building upon the leaders now in place and expanding their numbers, skills and capacities. The Information Linkages and Capacity Building framework (NDIS 2015a) has worthy intentions in this regard and has yet to be developed to a point where its purpose is fully understood and its effects are measurable. It remains to be seen whether this feature will live up to its billing, as there are significant constraining influences, mentioned above, that may curtail its intended effects. Nonetheless, the very fact that it was acknowledged in the early stages of the NDIS is a useful precedent to give legitimacy going forward. 


\section{People with a disability will need the involvement of family and friends}

In spite of the improvements over the past thirty years in the range of community-based services now available, many people with a disability have ended up with little more than formulaic, congregate care with few normal everyday relationships (Bigby, Bould and Beadle-Brown 2016). Not enough attention has gone into building an ordinary life in a social sense for the person, with all its ups and downs. In fact, 'service' has long been heralded as having greater importance than relationships and community belonging. Services can unwittingly and unconsciously cut across natural friendships and networks and contribute to isolating people from the many potential benefits and challenges of community life, ultimately to become a source of deprivation for people (Bigby et al. 2012, Kendrick 2011, Epstein-Frisch, Van Dam and Chenoweth 2006,). When it comes to vulnerable people, reliance on paid staff is often considered a more manageable and reliable substitute for the multitude of 'natural' types of relationships through which other people meet their everyday needs.

Agencies in the past have had to manage significant tensions between meeting the real needs of a person and keeping an under-funded service afloat. Nonetheless, in the formulation of this trade off, the contribution of families, friends and informal networks had been relegated to almost functional nonexistence, despite the fact that these people constitute ‘community'. The role of families was barely acknowledged in the DSA. Families were regarded, on the one hand, as a ready source of unpaid support and, on the other hand, as victims of circumstance requiring respite from the burden of caring (Burton-Smith et al. 2009). The NDIS Act attempts to rebalance this legacy with the rightful and critical acknowledgement of and respect for the role that family, friends and natural supporters can play in a person's life. The legislation specifically tasks the NDIS to 'strengthen, preserve and promote positive relationships between children and the people who are significant in 
their lives' (Commonwealth of Australia 2013, 8) and 'to respect the informal networks of adults' (Commonwealth of Australia 2013, 34).

There is evidence that service responses will potentially be less formulaic and custodial, particularly if people have a strong vision for themselves and they have the active and positive involvement of family and friends to help them (Lord and Hutchison 2003, Manthorpe et al. 2011, Howard et al. 2015). Nevertheless, working with families, friends and informal networks, particularly when the person is an adult, can be complex, time-consuming and messy, and many services have yet to develop the confidence and skill to embrace these complexities. These services might be tempted to revert to past practices and to take the easier path of paid staff and 'clienthood' as a proxy for the real life relationships, unless families and friends clearly define their contribution to the lives of their loved ones.

What the NDIS proposes with regard to family and community involvement will likely require long-term generational change; and the NDIS will benefit from consciously investing in young families. The NDIS through its Local Area Co-ordinators and planners could encourage them to build their informal networks of support as a priority at a young age and thus lay in place the foundation for sustaining and expanding such community connections. This has the long-term potential to render formal services as subordinate to these natural networks rather than somehow being a substitute for them.

\section{Independent advocacy will still be crucial for progress to be made}

It would be naïve to portray the NDIS, formal disability services and much of the generic resources of communities as necessarily always being faithful to people with a disability and their families. Indeed, this paper would suggest that this loss of fidelity to people with a disability has been endemic and is part of the problem why their lives have been so hard. The reforms in the past have resulted as much from people with a disability and resourceful 
leaders 'on the ground' speaking out (Gray and Jackson 2002, Cooper 1999) as from the worthy intentions of governments or powerful interests.

For at least thirty years, governments have seen benefit in funding advocacy support of various kinds, which has, in turn, called these governments and powerful interests to account. This has been much more the case when advocates have structural independence as a guiding principle, and where the source of funding for advocacy does not cause a conflict of interest for the advocates (Wolfensberger 2003). When serious conflicts of interest occur, they effectively dilute the independence of the advocacy and weaken, if not entirely block, the ability of people with a disability and their allies to defend their vital existential interests (Kendrick 2001).

One needs to ask who will support people with a disability in the future to challenge these powerful interests within the extended NDIS system, when they do not get it right. The case to be made by advocates will differ from the advocacy based on traditional welfare arguments of the past, although the essential issues of human rights and protection will prevail. A new language of disability economics will be required to keep the interests of people with a disability foremost within the insurance framework of the NDIS and the reliance on markets to solve problems (Frisch 2010). History tells us that the best systemic advocacy will be done by individuals and organisations with life-giving values and vision for people with a disability that remain focused, tenacious, and independent of vested interests (Wolfensberger 2003). Perhaps, it is time to consider how advocacy can be done differently, within a market-driven environment and without depending so heavily on the government grants of the past.

\section{Conclusion}

The NDIS 2013, like its predecessor, the DSA, provides once-in-a-generation legislative reform on how people with a disability are served. Its enactment should not be a surprise; 
policy change of this order happens only after decades of social action by resourceful and thoughtful leaders 'on the ground', working person by person, followed by determined social advocacy, and finally by the political will of a benevolent and visionary government. This paper sought to identify some lessons from the last time reform of this magnitude occurred to guide those who will implement the NDIS.

The initial blush of the NDIS honeymoon is over and the hard work now begins. Looking back at the journey from the DSA should prepare change agents somewhat for what is ahead. The lessons offered in this paper suggest that decades of investment in many sources, including people with a disability and their families, the community, government and the service system will be needed before there is real and lasting progress towards the meeting the valid objectives of the NDIS. If, on the other hand, it is assumed that progress will come quickly and easily, then we may be underestimating what it takes to get enduring, positive change in the real world for people with a disability and, regardless of the new funding and operational systems, people with a disability in Australia will continue to live less than optimal lives.

\section{Disclosure statement}

No potential conflict of interest was reported by the authors. 


\section{References}

Bartnik, E, and R Chalmers. 2007. "It's about more than the money: local area co-ordination supporting people with disabilities." In Co-production and personalisation in social care: changing relationships in the provision of social care, edited by S Hunter and $\mathrm{P}$ Ritchie. Jessica Kingsley Publishers.

Baume, P, and K Kay. 1995. Working solution: Report of the Strategic Review of the Commonwealth Disability Services Program. edited by Department of Human Services and Health \& Strategic Review of the Commonwealth Disability Services Program (Australia). Canberra: Australian Government Publishing Service.

Bigby, C, E Bould, and J Beadle-Brown. 2016. "Conundrums of supported living: The experiences of people with intellectual disability." Journal of Intellectual \& Developmental Disability:1-11, DOI 10.3109/13668250.2016.1253051.

Bigby, C, M. Knox, J. Beadle-Brown, T. Clement, and J. Mansell. 2012. "Uncovering Dimensions of Culture in Underperforming Group Homes for People with Severe Intellectual Disability." Intellectual and developmental disabilities 50 (6):452-467.

Bostock, L, and B. Gleeson. 2004. "Contested housing landscapes?: Social inclusion, deinstitutionalisation and housing policy in Australia." Australian Journal of Social Issues 39 (1):41-62.

Brown, C, and C Ringma. 1989. "Consumer perspectives on disability services in Queensland: The long road to new directions." Journal of Intellectual and Developmental Disability 15 (1):41-48.

Burke, L. 2012. "A journey with people towards self-direction." CRUcial Times June 2012 (43).

Burton-Smith, R, Keith R McVilly, M. Yazbeck, T. Parmenter, and T. Tsutsui. 2009. "Quality of life of Australian family carers: Implications for research, policy, and practice." Journal of policy and practice in intellectual disabilities 6 (3):189-198.

Chenoweth, L, and D Stehlik. 2004. "Implications of social capital for the inclusion of people with disabilities and families in community life." International Journal of Inclusive Education 8 (1):59-72.

Chenoweth, L. 2000. "Closing the Doors: Insights and Reflections on Deinstitutionalisation." Law in Context 17 (2):77-100.

Commonwealth of Australia. 1986. Disability Services Act. Canberra.

Commonwealth of Australia. 2013 National Disability Insurance Scheme Act. Canberra

Community Resource Unit. 2013. Together in partnership: Stories of individual and family governed organisations in Queensland (video). Brisbane.

Cooper, M. 1999. "The Australian disability rights movement lives." Disability \& Society 14 (2):217.

Coulson, S. 2007. "Person-centred planning as co-production." In Co-production and personalisation in social care: changing relationships in the provision of social care, edited by S Hunter and P Ritchie, 105-118. London: Jessica Kingsley Publishers.

DANA (Disability Advocacy Network Australia). 2016. "Issues." Accessed January 16, 2017. http://www.dana.org.au/home/issues-2/.

Davila, T., M. Epstein, R. Shelton, and R.D. Shelton. 2006. Making Innovation Work: How to Manage It, Measure It, and Profit from it: Wharton School Pub.

Department of Social Services. 2016. "National Disability Advocacy Program " Accessed January 16, 2017. https://www.dss.gov.au/our-responsibilities/disability-andcarers/program-services/for-people-with-disability/national-disability-advocacyprogram-ndap. 
Disability Services Commission. 2015. Individualised Funding Policy. Perth: Government of Western Australia.

Dyke, J. 2013. " Right relationships: The Homes West experience " Intellectual Disability Australasia 34, (1):3-8.

Epstein-Frisch, B, T Van Dam, and L Chenoweth. 2006. Presenting the Evidence: accommodation and support for people with disability. Sydney: Family Advocacy.

Every Australian Counts. 2013. "NDIS: revolutionising disability services." Accessed July 17, 2013. http://everyaustraliancounts.com.au/about/.

Ferguson, I. 2007. "Increasing User Choice or Privatizing Risk? The Antinomies of Personalization." The British Journal of Social Work 37 (3):387-403.

Finkelstein, V. 1981. "Disability and the helper/helped relationship: An historical view." Handicap in a social world:58-65.

Frisch, J. 2010. "Disability: the other person’s problem." Living Ethics (82):7, 12.

Frisch, Y. 2015. "Why disability advocacy matters under the NDIS." Accessed 21 March 2016 at http://www.everyaustraliancounts.com.au/opinion/why-disability-advocacymatters-under-the-ndis/.

Glendinning, C. 2008. "Increasing choice and control for older and disabled people: A critical review of new developments in England." Social Policy \& Administration 42 (5):451469.

Grattan, M. 2015. "Medicare co-payment: a case study in policy implosion" The Conversation Accessed 21 March 2016 at https://theconversation.com/medicare-copayment-a-case-study-in-policy-implosion-38311

Gray, B, and R Jackson. 2002. Advocacy and learning disability: Jessica Kingsley Publishers.

Handicapped Programs Review. 1985. New directions: Report of the Handicapped Programs Review. Canberra: Australian Government.

HDG Consulting Group. 2013. Evaluation of direct employment project. Melbourne.

Howard, A, T Blakemore, L Johnston, D Taylor, and R Dibley. 2015. "I’m not really sure but I hope it's better': early thoughts of parents and carers in a regional trial site for the Australian National Disability Insurance Scheme." Disability \& Society 30 (9):1-17.

Individualised Funding Coalition for Ontario. 2004. "Ask Me First: Advocacy for Voice and Choice." Accessed 21 March 2016 at

https://individualizedfunding.files.wordpress.com/2014/08/ask-me-first-advocacy-forvoice-and-choice.pdf.

Kendrick, M. 2001. "Some observations on the American advocacy scene." In Advocacy for people with learning disabilities, edited by B Gray and R Jackson, 189-205. London: Jessica Kingsley Publishers

Kendrick, M. 2009. Letting in the Light: Reflections on Leadership, Ethics, and Human Services: CRU Publications.

Kendrick, M. 2011. "Empowerment and Self Direction Relative to the Design and Governance of Personalized Service Arrangements." Journal of Human Development, Disability and Social Change 19 (2):57-68.

Kendrick, M. 2012. As the years pass: Reflections on the last twenty-five years and looking forward. Interaction, 25 (3):6-15.

Lakhani, A, D McDonald, and H Zeeman. 2016. "Perspectives of self-direction: a systematic review of key areas contributing to service users' engagement and choice-making in self-directed disability services and supports." Health \& Social Care in the Community.

Lemay, R. 1999. "Roles, identities, and expectancies: Positive contributions to normalization and social role valorization." A quarter-century of normalization and social role 
valorization: Evolution and impact, edited by R Flynn and R Lemay, 219-240. Ottowa: University of Ottowa Press.

Lindsay, M. 1996. Background paper 2 1995-96: Commonwealth Disability Policy 19831995. In Social Policy Group, Parliamentary Library of Australia, Canberra: Parliament of Australia.

Lord, J, and P Hutchison. 2003. "Individualised support and funding: building blocks for capacity building and inclusion." Disability \& Society 18 (1):71-86.

Manthorpe, J, J Hindes, S Martineau, M Cornes, J Ridley, H Spandler, A Rosengard, S Hunter, S Little, and B Gray. 2011. Self-directed support: A review of the barriers and facilitators. Edinburgh: Scottish Government.

Mavromaras, K, M Moskos, and S Mahuteau. 2016. Evaluation of the NDIS: Intermediate report. Adelaide, South Australia: National Institute of Labour Studies, Flinders University.

National Disability Practitioners. 2014. "Getting started." National Disability Services. Accessed 21 March 2016 at http://www.ndp.org.au/ndis-getting-started.

National Disability Services. 2015. State of the Disability Sector Report. Canberra: National Disability Services.

National Institute of Labour Studies. 2015. "Evaluation of the Trial of the National Disability Insurance Scheme." Accessed 21 March 2016 at http://ndisevaluation.net.au/.

National People with Disabilities and Carer Council. 2009. "Shut Out: The Experience of People with Disabilities and their Families in Australia." Canberra: Australian Government.

NDIA. 2016. Towards an ordinary life: Annual Report 2015-2016. edited by National Disability Insurance Agency. Canberra.

NDIS. 2015. "IAC advice to the NDIA Board and Agency response." National Disability Insurance Scheme. Accessed 21 March 2016 at http://www.ndis.gov.au/aboutus/governance/IAC/IAC-advice-2015-NDIA-response.

NDIS. 2015a. A Framework for Information, Linkages and Capacity Building. Canberra: Australian Government.

NDIS. 2015b. Proposal for a National Disability Insurance Scheme Quality and Safeguarding framework. Canberra: NDIS Senior Officials Working Group for the Disability Reform Council, Australian Government.

Nirje, B (1969) "The Normalisation Principle and its Human Management Implications" in R Kugel and W Wolfensberger (eds) Changing Patterns in Residential Care for the Mentally Retarded. Washington: President's Committee on Mental Retardation.

Office of Disability. 1987. Disability, society and change: a resource kit explaining the Commonwealth Government Statement of principles and objectives. Sydney: Office of Disability.

Ottmann, G, C. Laragy, and M. Haddon. 2009. "Experiences of disability consumer-directed care users in Australia: results from a longitudinal qualitative study." Health \& Social Care in the Community 17 (5):466-475.

Piketty, T, and E Saez. 2014. "Inequality in the long run." Science 344 (6186):838-843.

Productivity Commission. 2011. Disability Care and Support: Productivity Commission inquiry report. Canberra: Australian Government.

RichmondPRA. 2013. Good practice guidelines for person-centred planning and goal setting for people with psychosocial disability: A project report for DisabilityCare Australia [National Disability Insurance Scheme]. Sydney: RichmondPRA.

Robinson, S, and L Chenoweth. 2011. "Preventing abuse in accommodation services: From procedural response to protective cultures." Journal of Intellectual Disabilities 15 (1):63-74. 
Roulstone, A, and H Morgan. 2009. "Neo-liberal individualism or self-directed support: are we all speaking the same language on modernising adult social care?" Social Policy and Society 8 (03):333-345.

Social Care Institute for Excellence. 2015. "Care Act 2014: Advocacy principles and standards." Accessed 21 March 2016 at http://www.scie.org.uk/care-act2014/advocacy-services/commissioning-independent-advocacy/inclusionempowerment-human-rights/principles-standards.asp.

Stainton, T, and H. Besser. 1998. "The positive impact of children with an intellectual disability on the family." Journal of Intellectual \& Developmental Disability 23 (1):57-70.

Swaine, J, S Parish, L Igdalsky, and R Powell. 2016. "Consumers' and workers' perspectives about consumer-directed services in the United States." Disability and Health Journal 9 (3):464-471.

Swann, W, J Gillard, and J Macklin. 2013. Locking in a fairer future for Australians with disability. In The Treasury, edited by Australian Government. Canberra.

Timberlake, M, W Leutz, M Warfield, and G Chiri. 2014. "“In the Driver's Seat”: Parent Perceptions of Choice in a Participant-Directed Medicaid Waiver Program for Young Children with Autism." Journal of autism and developmental disorders 44 (4):903914.

Tingle, L. 2012. “Great expectations: government entitlement and an angry nation." Quarterly Essay 46 Vol. 43: Black Inc.

United Nations. 1971. "Declaration on the Rights of Mentally Retarded Persons."

United Nations. 1975. "Declaration on the Rights of Disabled Persons."

United Nations. 2007. "Convention on the rights of persons with disabilities and optional protocol."

Ward, M. 2006. "The vision of the Disability Services Act 1986: A never-ending struggle." Journal of Intellectual and Developmental Disability 31 (4):253-254.

Weatherley, R. 1994. "From entitlement to contract: Reshaping the welfare state in Australia." Journal of Sociology \& Social Welfare 21:153-174.

Wiesel, I, and C Bigby. 2015. "Movement on shifting sands: Deinstitutionalisation and people with intellectual disability in Australia, 1974-2014." Urban Policy and Research 33 (2):178-194.

Wills, R, and L Chenoweth. 2005. "Support or compliance." In Allies in Emancipation: Shifting from Providing Service to Being of Support, edited by P O'Brien and M Sullivan, 49-64. Melbourne: Thomson Learning.

Wolfensberger, W. 1983. "Social Role Valorization: A proposed new term for the principle of normalization." Mental Retardation 21 (6):234-239.

Wolfensberger, W. 1998. A brief introduction to social role valorization: A high-order concept for addressing the plight of societally devalued people, and for structuring human services (3rd ed.). Syracuse, USA: Training Institute for Human Service Planning, Leadership and Change Agentry (Syracuse University).

Wolfensberger, W. 2003. "Advocacy." In Leadership and change in human services: Selected readings from Wolf Wolfensberger, edited by D. Race, 119-149. London: Psychology Press. 